\title{
Evidence for Directional Wind Response in Controlling Inter-annual Variations in Duration and Areal Extent of Summertime Hypoxia in Western Long Island Sound
}

\author{
Robert E. Wilson • Sean D. Bratton • Jindong Wang • Brian A. Colle
}

Received: 28 June 2013 /Revised: 24 July 2014 / Accepted: 31 October 2014 / Published online: 3 December 2014

(C) The Author(s) 2014. This article is published with open access at Springerlink.com

\begin{abstract}
Observations of summertime hypoxia duration and hypoxia areal extent in western Long Island Sound from 1991 to 2010 are correlated with local wind forcing. Results show a strong dependence on wind direction consistent with straining due to axial winds. The analysis of current data from moored ADCPs in the western Sound shows that the dominant mode of response is that of axial currents to axial winds. Estimates for the Wedderburn number $(W)$ are relatively low ranging from 0.75 to 2.5 for prevailing winds, putting the western Sound in a regime more dominated by wind straining than by wind mixing. Estimates for the Kelvin number $(\mathrm{Ke})$ range from approximately 1 to 6 in this diverging channel suggesting the importance of rotation; in the wide part of the basin, current observations show that significant vertically sheared lateral currents develop consistent with the tilting of planetary vortex lines by wind-driven axial current shear. Lateral straining, however, offsets longitudinal straining in the wide part of the basin supporting the hypothesis that simple longitudinal straining associated with axial winds exerts the most important control on the development summertime hypoxia in the constricted part of the western Sound.
\end{abstract}

Keywords Hypoxia duration · Hypoxic area · Wind · Straining

\section{Introduction}

Wind straining of the density field can exert first-order control on vertical density stratification and thereby play an important

Communicated by William Boicourt

R. E. Wilson $(\bowtie) \cdot$ S. D. Bratton · J. Wang • B. A. Colle

School of Marine and Atmospheric Sciences, Stony Brook

University, Stony Brook, NY 11794-5000, USA

e-mail: robert.wilson@stonybrook.edu role in modulating vertical mixing in a partially mixed estuary. Observational studies such as that by Scully et al. (2005) in the York River estuary, idealized modeling (Chen and Sanford, 2009), and regional modeling in the Chesapeake Bay by Li and $\mathrm{Li}$ (2011) are enlightening examples from extensive literature on wind straining. It is important to acknowledge that the consequences of wind straining of the salinity field were discussed much earlier by Weisberg (1976), in light of observations in Narragansett Bay. Also, as part of a modeling study of Charlotte Harbor, Weisberg and Zheng (2003) had described the basic mechanism of wind straining by which winds can rotate isolines toward the vertical and thereby reduce stratification and increase vertical mixing. Both O'Donnell et al. (2008) and Wilson et al. (2008) have suggested that straining of the density field by axial winds plays an important role in controlling seasonal hypoxia in western Long Island Sound (LIS) by modulating vertical mixing. More recently, Scully (2010a) demonstrated that inter-annual variations in the summertime volume of hypoxic water in the Chesapeake Bay are positively correlated with the duration of westerly winds and negatively correlated with the duration of southeasterly winds. A numerical process-oriented study by Scully (2010b) demonstrated that the extent of hypoxia in the Chesapeake is indeed strongly influenced by wind direction. The study demonstrated also that the extreme sensitivity of hypoxic volume to wind direction is associated with interactions between lateral wind-driven circulation, bathymetry, and vertical mixing. A related study by Forrest et al. (2011) has shown that wind has a significant effect on the inter-annual variance in the areal extent of seasonal hypoxia over the Texas-Louisiana shelf, independent of riverine processes. The statistical relationship between westerly winds and decreasing hypoxic area was explained through effects of the wind on the Mississippi/Atchafalaya river plume system (Hetland and DiMarco 2008).

Figure 1 shows a comparison of histograms for summertime wind speed and direction at LaGuardia Airport (Fig. 2) 
Fig. 1 Histograms for July/August winds at LaGuardia during a severe hypoxia year 1988 and a non-hypoxia year $1990(\mathbf{a}, \mathbf{b})$

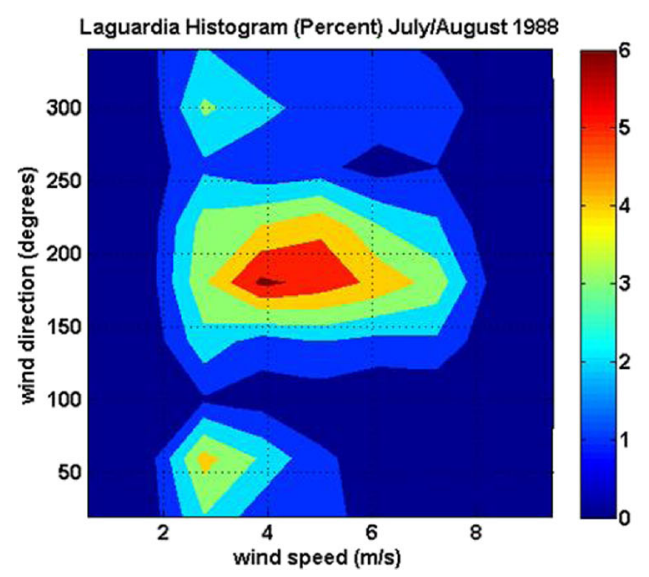

for a severe hypoxia year (1988) in western LIS waters and a non-hypoxia year (1990). The severe hypoxia year was characterized by persistent southerly winds, while non-hypoxia year was characterized by marked increase in the frequency of northeasterly winds, with no discernible difference in median wind speeds. The direction histogram for summertime winds (Fig. 3) indicates, in fact, that there are two distinctive directional peaks whose relative strength exhibits inter-annual variability over the period 1980-2010. The predominant direction is from the SSW and is associated with the stationary summertime Bermuda high-pressure system. The other major directional peak is for winds from the NE; a third but much weaker peak is associated with winds from the NW. As discussed later, these peaks are associated with synoptic period events. The primary objective of this study is to test the hypothesis that summer wind direction explains a significant fraction of the inter-annual variability in two important metrics associated with recurring hypoxia in western LIS (Fig. 4):

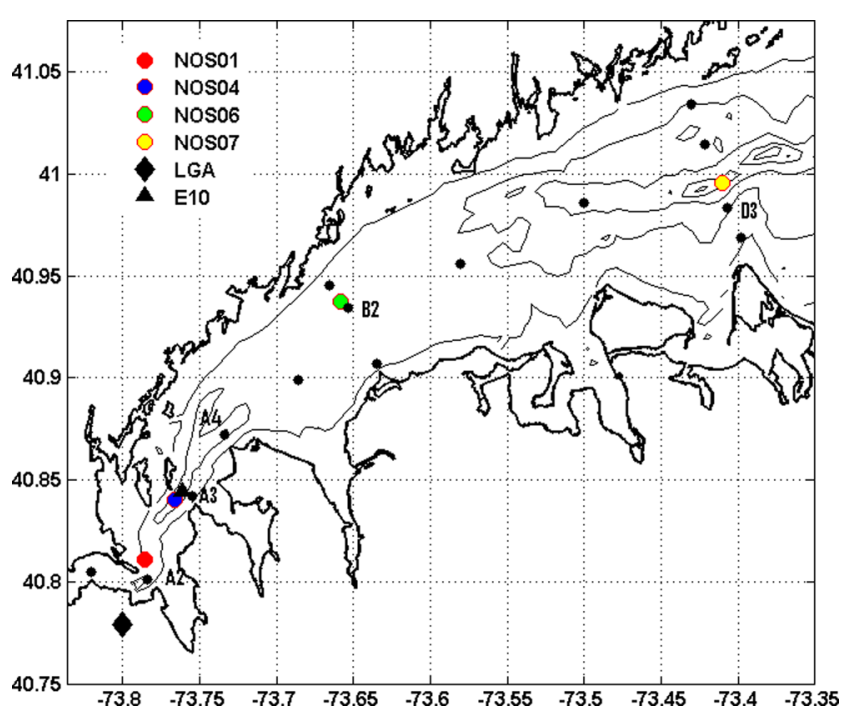

Fig. 2 Western LIS showing locations of NOS ADCP moorings, NOS hydrographic stations (solid black circles with channel stations labeled $A 2, A 3, B 2, D 3)$, NYC DEP station E10, and LaGuardia Airport. Isobaths are at $10-\mathrm{m}$ intervals beginning at $10 \mathrm{~m}$ duration and areal extent. A secondary objective is to determine whether simple straining due of the axial density gradient by axial winds is primarily responsible for ventilation as suggested by O'Donnell et al. (2008) and Wilson et al. (2008), or whether lateral straining due to lateral winds can also be important as suggested by Scully (2010b).

\section{Data and Methods}

We base our analyses primarily on time series for the duration and areal extent of summertime hypoxia in LIS developed by the Connecticut Department of Environmental Protection (CTDEP) for 1991-2009. CTDEP typically occupies 35 water quality stations distributed throughout LIS biweekly during summer months. A detailed description of sampling protocols, instrumentations, and methods for defining the hypoxia duration and areal extent from the observations as well as the duration and areal extent time series themselves may be found in CTDEP (2009).

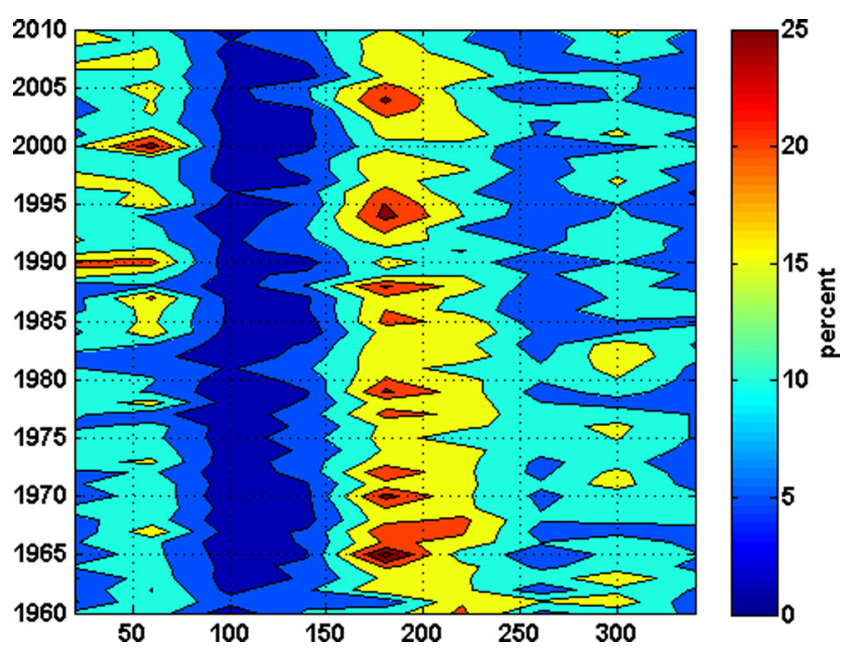

Fig. 3 Directional histogram for July/August winds at LaGuardia 
Fig. 4 Frequency of hypoxia in LIS bottom waters (from CTDEP 2009)

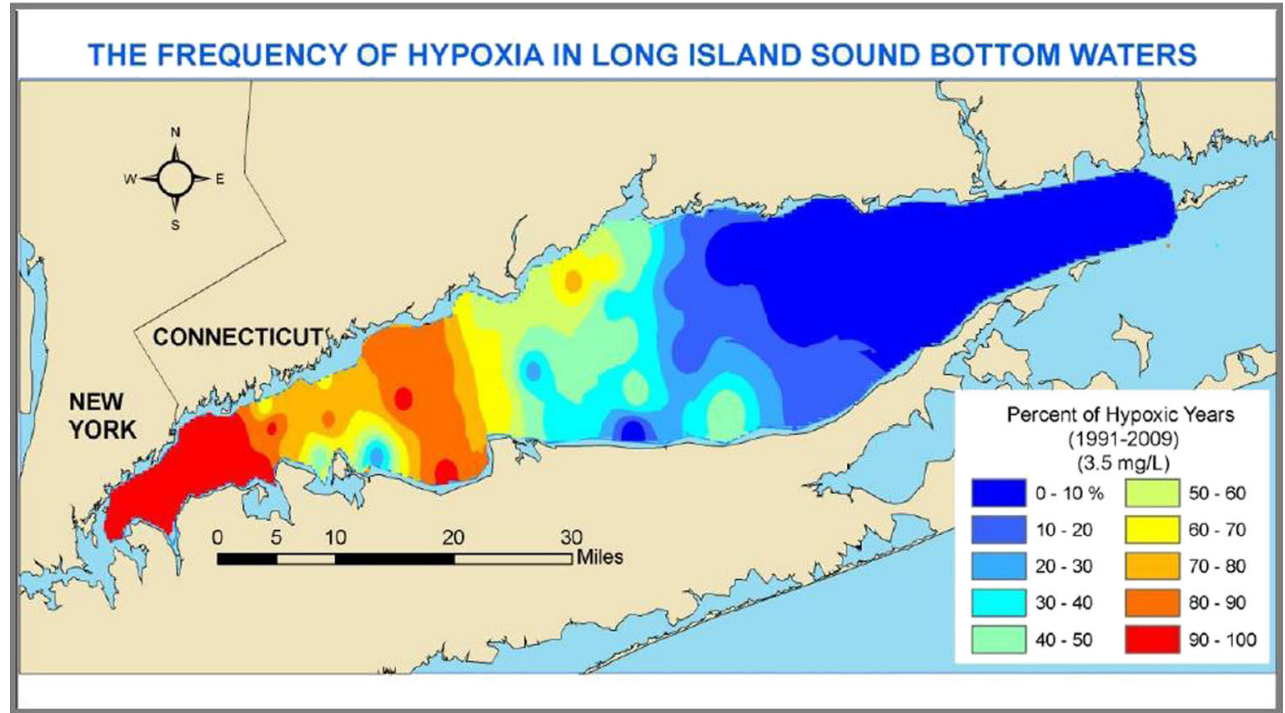

We also analyzed the time series of hypoxia duration at a single long-term station E10 in western LIS (Fig. 2) maintained by the New York City Department of Environmental Protection (NYC DEP). E10 is the easternmost of the NYC DEP Harbor survey stations located in the western narrows of LIS. This is an important station because it is in an area with chronic severe summertime hypoxia, and it is the station analyzed by Wilson et al. (2008) who describe sampling protocols and instrumentations. Dissolved oxygen data are available for E10 from 1946 to 2010, but for the present study, we use data only from 1988 to 2010 because beginning in 1988, with the initiation of the USEPA LIS Study, there was a change in sampling protocol, and the Winkler method was used almost exclusively to measure dissolved oxygen. Analogous to the CTDEP duration estimate, summertime hypoxia duration at E10 is defined as the total length of time; the observed bottom dissolved oxygen was below $3.5 \mathrm{mg} / \mathrm{l}$; this duration was estimated using simple linear interpolation in time between the observed data points.

Inter-annual variations in CTDEP estimates for hypoxia duration and areal extent for 1991-2009 and NYC DEP E10 hypoxia duration for 1988-2010 were correlated with changes in summertime wind direction using hourly observations available for the NWS station at LaGuardia Airport (Fig. 2). The specific analyses involved computing the correlation and associated $p$ values between the duration or areal extent time series and the percent of summer winds in different directional bins. For the CTDEP estimates of duration, the earliest hypoxia start date was June 20 and the latest hypoxia end date was September 26. For the NYC DEP estimates of duration, the earliest hypoxia start date was June 19 and the latest hypoxia end date was September 29.

Four acoustic Doppler current profiler (ADCP) moorings in western LIS in areas subject to persistent summertime hypoxia (Fig. 2; Table 1) were analyzed to establish the relationship between sub-tidal variations in exchange flow and axial winds. Scully et al. (2005) found, for example, that in the York River variations in exchange flow, stratification, and vertical eddy diffusivity were highly correlated with one another and with axial winds. These western LIS moorings had been deployed as part of a NOS circulatory survey (Earwaker 1990). We also applied empirical orthogonal

Table 1 Regression between axial wind and exchange flow at NOS western LIS ADCP mooring; principal axis heading defines the local axial direction

\begin{tabular}{|c|c|c|c|c|c|}
\hline NOS ADCP mooring & Station depth $(\mathrm{m})$ & Heading $\left(^{\circ}\right)$ & Regression coefficient & Intercept $<\Delta U>(\mathrm{m} / \mathrm{s})$ & $R$ \\
\hline $\begin{array}{l}\text { NOS01 } \\
\text { May 03-July 10, } 1988\end{array}$ & 15.9 & 9 & 0.014 & 0.153 & 0.78 \\
\hline $\begin{array}{l}\text { NOS01 } \\
\text { July } 12-\text { December } 31,1988\end{array}$ & 15.9 & 8 & 0.017 & 0.147 & 0.85 \\
\hline $\begin{array}{l}\text { NOS04 } \\
\text { May 03-June 07, } 1988\end{array}$ & 35.4 & 34 & 0.024 & 0.102 & 0.89 \\
\hline $\begin{array}{l}\text { NOS06 } \\
\text { May 03-June 07, } 1988\end{array}$ & 19.2 & 55 & 0.039 & 0.066 & 0.85 \\
\hline $\begin{array}{l}\text { NOS07 } \\
\text { May 06-July 16, } 1990\end{array}$ & 45.0 & 59 & 0.021 & 0.142 & 0.79 \\
\hline
\end{tabular}


Fig. 5 Correlation and $p$ values between CTDEP hypoxia duration and percent of winds from different directions for 1991-2009 and the same correlations including random noise (see text) $(\mathbf{a}, \mathbf{b})$
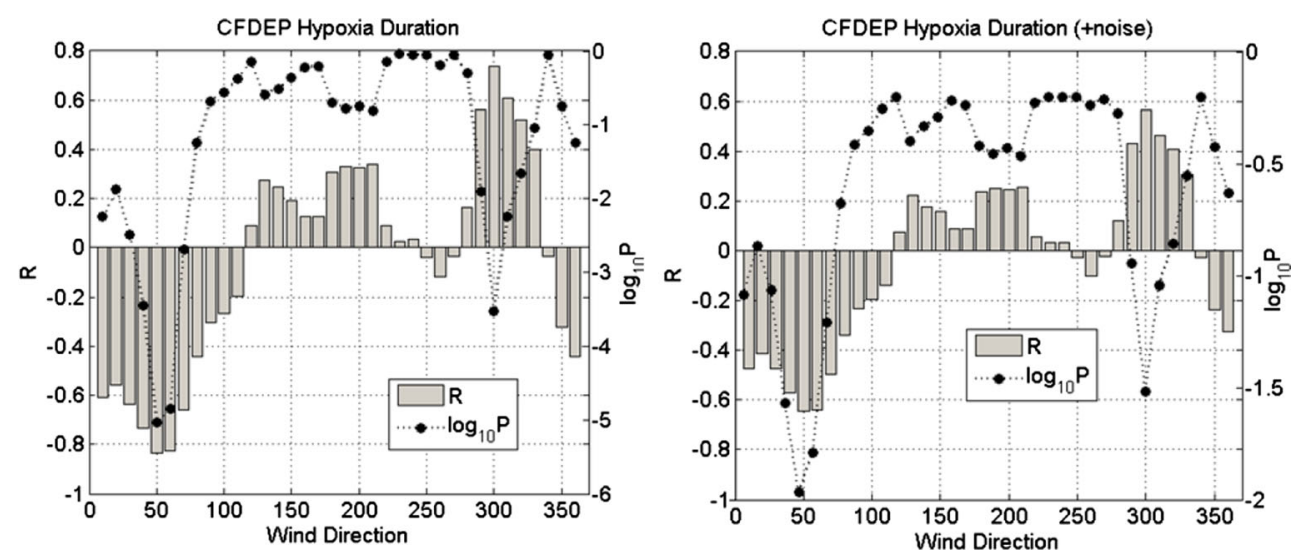

function (EOF) analysis to the 34-h low-pass filtered currents at these moorings with the objective of the refining description of the directional response of sub-tidal current fluctuations to winds. CTD observations collected as part of the same circulatory survey (Fig. 2) provided information on background water column stratification from which the Kelvin number $(\mathrm{Ke})$ could be estimated. As discussed below, this contributes to an assessment of the influence of rotation on the directional response of currents in this rapidly diverging channel.

\section{Results}

Wind Direction and Hypoxia Duration and Areal Extent

The correlation and associated $p$ values between inter-annual variations in CTDEP hypoxia duration estimates and the percent of hourly summer winds from different directions for 1991-2009 are shown in Fig. 5. Time series were developed for percent of hourly winds in $40^{\circ}$ bins with increments of $10^{\circ}$; the first bin is $0-40^{\circ}$, the second $10-50^{\circ}$, etc. We found that using wind data from June 01 to September 10 for each year and wind speeds above $3.5 \mathrm{~m} / \mathrm{s}$ maximized correlations and minimized $p$ values. Remarkably high negative correlations and low $p$ values are found for winds from the northeast.
For winds in a $40^{\circ}$ bin centered on $50^{\circ}$, the correlation with hypoxia duration is -0.83 with a $\log _{10}$ ( $p$ value) of -5.03 . High positive correlations and low $p$ values are also found for winds from the northwest. For winds in a $40^{\circ}$ bin centered on $300^{\circ}$, correlation with hypoxia duration is +0.74 with a $\log _{10}$ ( $p$ value) of -3.53 . Correlations with winds from other quadrants are not significant.

O'Donnell (2013, personal communication) has emphasized that observations from moorings in western LIS lead him to expect that CTDEP monitoring observations from stations with strong tidal currents and significant horizontal gradients may be aliased. This aliasing could contribute to uncertainty in metrics such as seasonal hypoxia duration. To address the effects of possible or even likely uncertainty in duration, for example, we tested the effects of random noise on the correlations of $p$ values. Figure 5 shows the revised correlations obtained by adding random noise with a standard deviation of 10 days to the duration and taking an ensemble average over 100 realizations. The peak correlations are reduced to 0.63 , but the $p$ values indicate that correlations are still significant.

Estimates of the correlation between inter-annual variations in hypoxia duration at NYC DEP station E10 in the western narrows and winds in different directional bins (Fig. 6) afford a comparison with response inferred from the distributed
Fig. 6 Correlation (upper) and $p$ values (lower) between NYC DEP E10 hypoxia duration and percent of winds from different directions for 1988-2010 and between CTDEP hypoxia areal extent and percent winds for 1991-2009 (a, b)
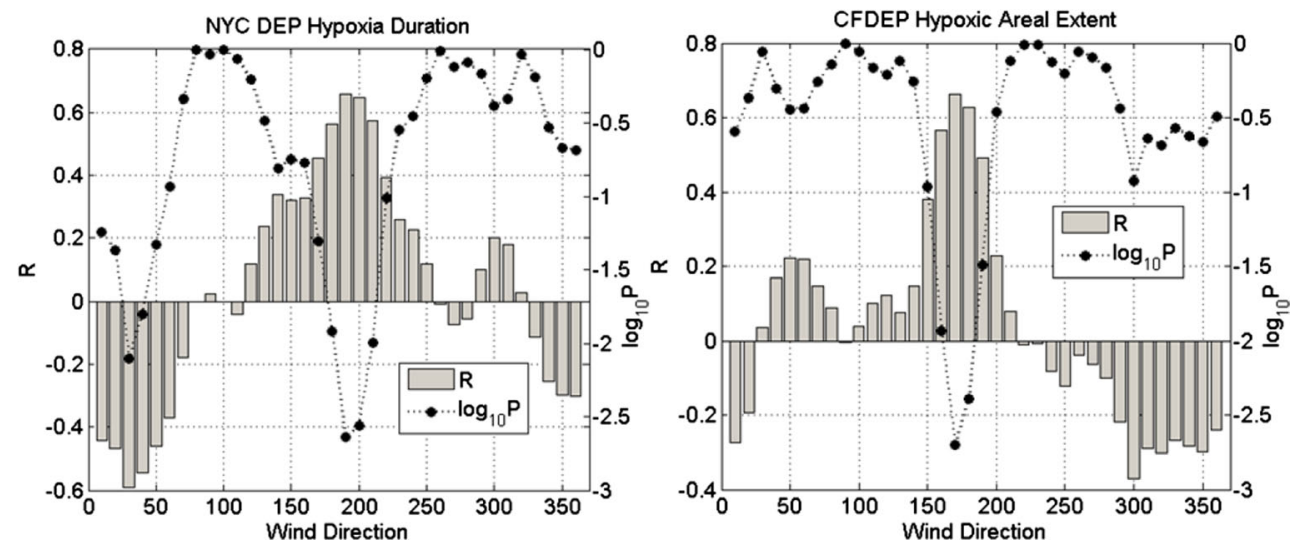
Fig. 7 Vertical structure of mean axial currents at NOS01 July 12 December 31, 1988 and NOS07 May 06-July 16, 1988
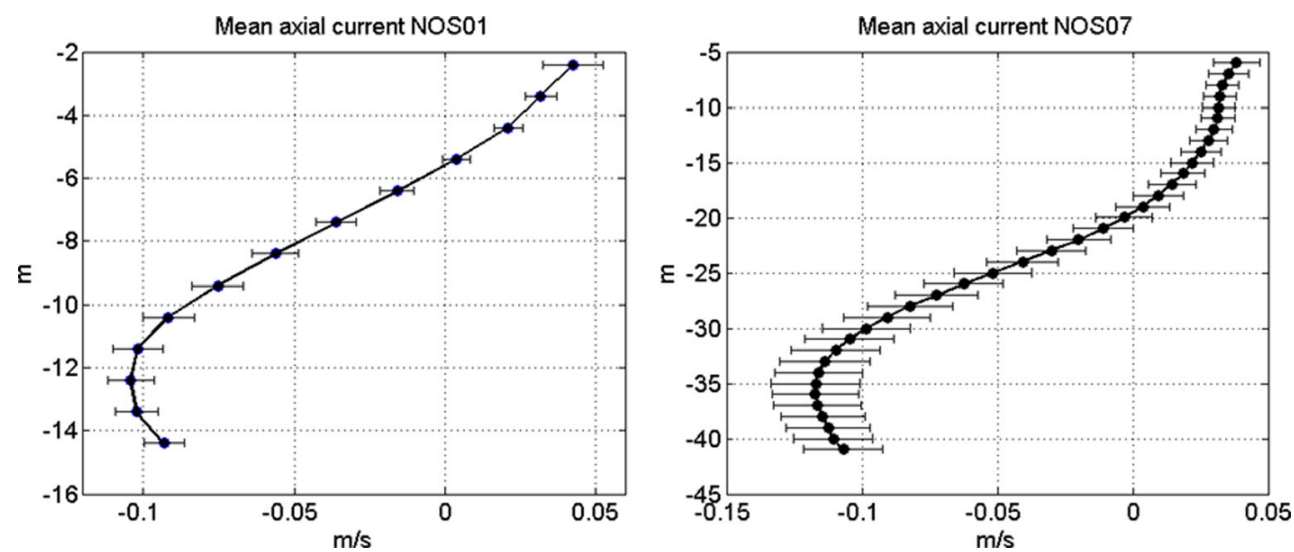

CTDEP stations. Results emphasize the effects of the constricted channel in the western narrows. Significant correlation peaks are found for essentially axial winds from $30^{\circ}(R=$ $-0.60 ; \log _{10}(p$ value $\left.)=-2.11\right)$ and $190^{\circ}\left(R=+0.66 ; \log _{10}(p\right.$ value $)=-2.6$ ). Correlations with winds from other quadrants are not significant.

The correlation between inter-annual variations in CTDEP hypoxia areal extent estimates for 1991-2009, and summer wind direction shows only one significant peak (Fig. 6) for southerly winds from $170^{\circ}\left(R=+0.67 ; \log _{10}(p\right.$ value $\left.)=-2.71\right)$.

\section{Exchange Flow and Axial Winds in Western LIS}

At each of the four moorings located (Fig. 2), the vertical profile of mean non-tidal axial current indicates a welldeveloped two-layer gravitational circulation with velocities of the order $10 \mathrm{~cm} / \mathrm{s}$; vertical profiles for mean axial currents NOS01 and NOS07 are shown in Fig. 7. The axial direction at each mooring was defined as the principal axis direction for the depth averaged tidal current; this heading increases from $9^{\circ} \mathrm{T}$ at NOS01 to $59^{\circ} \mathrm{T}$ at NOS07 (Table 1). Error bars provide an estimate of the standard error.
To quantify the influence of axial winds on exchange flow in western LIS, we followed Scully et al. (2005) and regressed exchange flow at each mooring defined as difference between the near-surface and near-bottom axial currents (Figs. 8 and 9) against axial wind. Results presented in Table 1 indicate correlations as high as 0.89 between exchange flow and axial wind. In this simple regression model, the constant intercept represents the mean density-driven exchange flow, and the variable linear term represents the wind-induced fluctuation. These two contributions permit an estimation of the Wedderburn number $(W)$ characterizing the effectiveness of wind straining in different sections of the channel as discussed below.

\section{Directional Wind Response at Current Moorings in Western} LIS

To complement the analysis of exchange flow and axial winds, EOF analysis was applied to 34-h low-pass filtered currents at each mooring to describe the vertical structure of both axial and lateral components of wind-driven current fluctuations and the directional relationship to wind forcing.
Fig. 8 Time series for low-pass filtered exchange flow defined as difference between axial current at 2.4 and $12.4 \mathrm{~m}$ and axial wind at NOS01 August 01-October 16, 1988

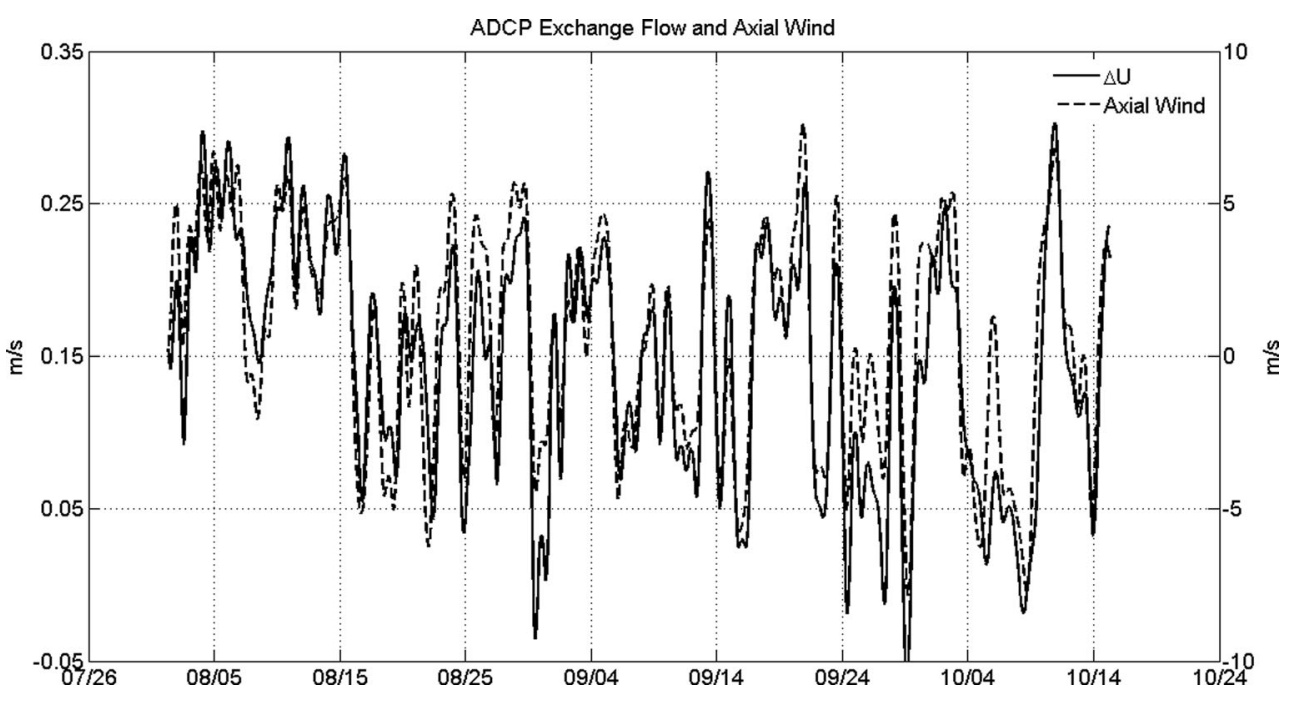


Fig. 9 Time series for low-pass filtered exchange flow defined as difference between axial current at 6.5 and $34.5 \mathrm{~m}$ and axial wind at NOS07 May 06-July 16, 1988

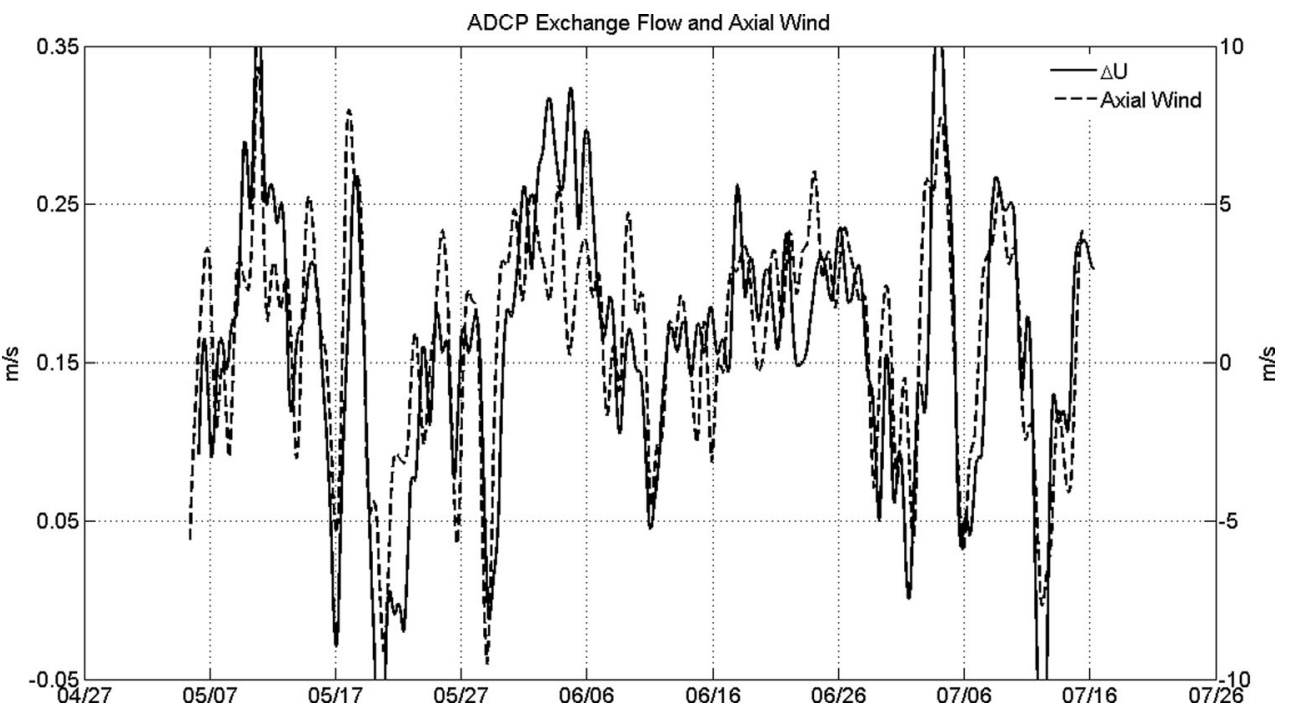

Axial and lateral components are analyzed together in the same EOF. The first mode eigenvector at all four moorings represents a vertically sheared axial current (Fig. 10), and the first mode principal components were highly correlated with axial winds (Table 2). At moorings in the western narrows (NOS01, NOS04), there was no contribution from the lateral component in the first mode, but at moorings in the wider section (NOS06, NOS07), the lateral contribution becomes significant (Fig. 10). At moorings NOS04 and NOS06, a weak second mode represented the lateral component with surfaceintensified shear with no contribution from the axial component. These second mode principal components were highly correlated with lateral winds.

EOF analysis of axial and lateral components separately provided additional insight into directional response and possible influence of rotation. The vertical structure of the first mode for the axial components was essentially the same as that from the combined analysis, and the principal components were again correlated with axial winds. The vertical structure for the first mode for the lateral components exhibit surface-intensified shear, but the directional response changes markedly depending on channel width. In the western narrows, the lateral current component responds directly to lateral winds. Proceeding eastward into the widening channel, the lateral component becomes more responsive to axial winds; at NOS07, the lateral current component responds almost directly to axial winds (Table 3 ).

\section{Discussion}

The strong dependence of exchange flow at moorings in western LIS on axial winds confirmed a relationship that had been demonstrated by Scully et al. (2005). It has, in fact, long been recognized (Weisberg 1976) that a dominant mode of wind response for a partially mixed estuary is that of axial currents to axial winds. The regression model for exchange flow reported in Table 2 partitions the exchange flow into components which can be associated with gravitational and a wind-driven circulation. Following logic of Chen and Sanford (2009) (CS), expressing the scale of vertical shear associated with the estuarine exchange flow $\Delta U$ in terms of the scales for
Fig. 10 Vertical structure of axial and lateral components for mode 1 eigenvectors for low-pass filtered currents at moorings NOS01 and NOS07 from vector $\mathrm{EOF}(\mathbf{a}, \mathbf{b})$
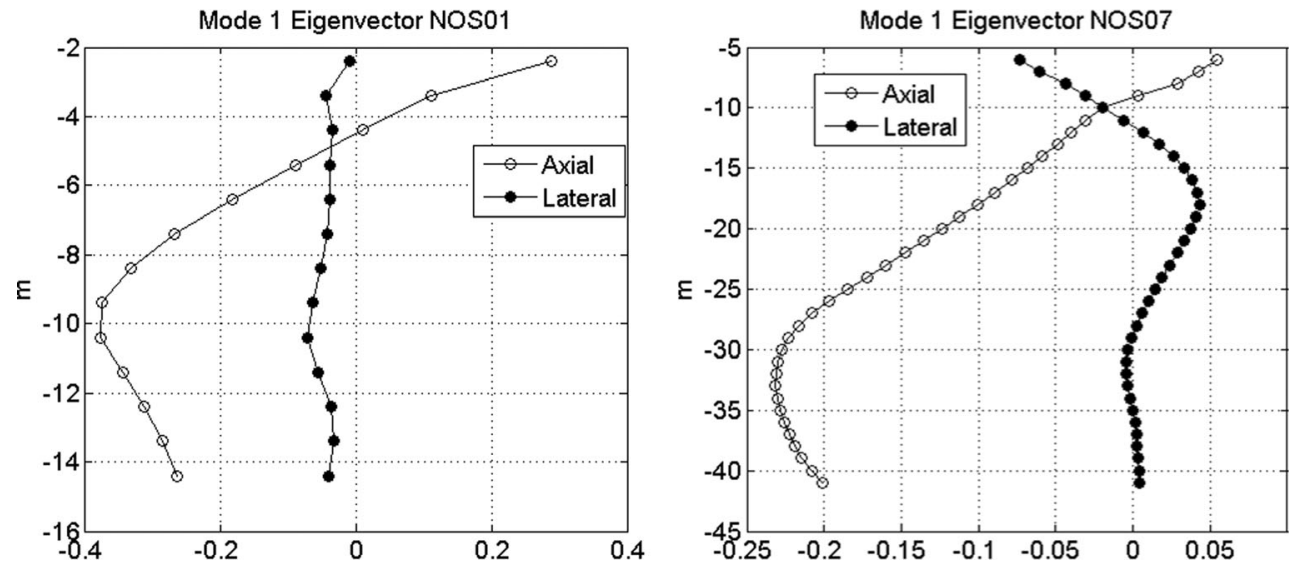
Table 2 EOF analysis applied to axial and lateral velocity components combined at NOS ADCP moorings, including variance fraction and results of correlation analysis between principal components and wind; defining the wind direction (oceanographic convention) which maximizes correlation

\begin{tabular}{lll}
\hline NOS station & $\begin{array}{l}\text { Mode 1 } \\
\text { variance (\%) }\end{array}$ & $\begin{array}{l}\text { Mode 1 PCA } \\
\text { Correlation } \\
\text { and heading }\end{array}$ \\
\hline NOS01 & 73 & 0.73 \\
May 03-July 10, 1988 & 74 & $11^{\circ}$ \\
NOS01 & & 0.72 \\
July 12-December 31, 1988 & 62 & $12^{\circ}$ \\
NOS04 & & 0.92 \\
May 03-June 07, 1988 & 60 & $39^{\circ}$ \\
NOS06 & & 0.85 \\
May 03-June 07, 1988 & 83 & $68^{\circ}$ \\
NOS07 & & 0.84 \\
May 06-July 16, 1990 & & $58^{\circ}$
\end{tabular}

gravitational and wind-driven circulation $u_{\mathrm{g}}$ and $u_{\mathrm{w}}$, we can use regression parameters in Table 2 to estimate $W$ which gauges the extent to which winds can significantly modify the estuarine circulation and stratification in western LIS:

$\Delta U \cong u_{\mathrm{g}}+u_{\mathrm{w}}=u_{\mathrm{g}}(1-\alpha W)$

$\Delta U=a_{0}+a_{1} U_{\mathrm{w}}$

$\alpha W=a_{1} U_{\mathrm{w}} / a_{0}$

Here, $a_{0}$ and $a_{1}$ are regression coefficients in Table $2, U_{\mathrm{w}}$ is axial wind velocity, and $\alpha$ is a geometric scaling factor. Scaling for $u_{\mathrm{g}}$ and $u_{\mathrm{w}}$ is given by Hansen and Rattray (1965) (HR) and by Officer (1976) (O); they show that for channels of rectangular cross-section $\alpha=12$, but as emphasized by CS, this scaling is indeterminate for natural cross-sections. Assuming that the shear associated with $u_{\mathrm{g}}$ and $u_{\mathrm{w}}$ cancel out during an up-estuary wind $U_{\text {w0 }}$ when $W \sim 1$ (CS), we have then that $\alpha=a_{1} U_{\mathrm{wo}} / a_{0}$ which is of order 1 by definition, giving:

$W=a_{1} \mathrm{U}_{\mathrm{w}} / a_{0}$.

This relation implies that in the vicinity of moorings NOS01 and NOS07, $W$ varies from approximately 0.75 to 1.25 for axial wind speeds varying from 5 to $10 \mathrm{~m} / \mathrm{s}$. In the vicinity of the deep channel mooring NOS04, $W$ varies from approximately 1.25 to 2.5 for the same winds. Station NOS06 is located on the very shallow Hempstead Sill cross-section, and estimates for $W$ are significantly higher. These estimates for $W$ are consistent with direct estimates based on the observed longitudinal density gradient of $2.5 \times 10^{-5} \mathrm{~kg} / \mathrm{m}^{4}$ and a scale depth of $20 \mathrm{~m}$. They indicate that winds can significantly modify the shear associated with estuarine circulation and stratification in western LIS but that western LIS is significantly less responsive than the Chesapeake where, for example, $W$ varies from approximately 1 to 6 for wind speeds varying from 5 to $10 \mathrm{~m} / \mathrm{s}(\mathrm{Li}$ and $\mathrm{Li}$ 2011). Importantly, the range of $W$ encountered for axial wind speeds varying from 5 to $10 \mathrm{~m} / \mathrm{s}$ places western LIS near the border separating a mixing dominated from a strainingdominated regime which was shown by CS to be $W \sim 1.8$.

Results from EOF analysis emphasize that although the dominant response was a vertically sheared axial current responding to axial winds, in the wider part of the section, axial winds produce significant lateral current fluctuations (Fig. 10). The shear associated with these lateral current fluctuations is consistent with that produced by a winddriven axial current shear through tilting planetary vorticity as described by Li and Li (2012). Following Garvine (1995), these authors discuss the strength of this rotational tendency in terms of the Kelvin number $K e=B f / c$ defined here as the ratio of channel width $B$ to internal radius $c / f$. Table 4 presents estimates of $\mathrm{Ke}$ obtained using available hydrographic data from channel stations occupied during the ADCP deployments. The channel width $B$ used is the approximate surface width which includes very shallow waters and may be an overestimate of an appropriate width to be compared with the internal radius. The phase speed estimated from these station data varies from 0.15 to $0.28 \mathrm{~m} / \mathrm{s}$, so the internal radius varies from 1.6 to $2.9 \mathrm{~km}$. Primarily, because of the channel width variations, $\mathrm{Ke}$ increases from approximately 1 in the western narrows to over 6 in the vicinity of NOS07. Accordingly, in the wider channel sections, we expect significant increase in the importance of rotation and specifically in the production of lateral current fluctuations through the vortex tilting mechanism discussed above (Table 4).

Table 3 EOF analysis applied separately to $U$ (axial) and $V$ (lateral) velocity components at NOS ADCP moorings, including variance fraction and results of correlation analysis between principal components and wind; defining the wind direction (oceanographic convention) which maximizes correlation

\begin{tabular}{|c|c|c|c|c|}
\hline $\begin{array}{l}\text { NOS ADCP } \\
\text { mooring }\end{array}$ & $\begin{array}{l}U \text { mode } 1 \\
\text { variance } \\
(\%)\end{array}$ & $\begin{array}{l}V \text { mode } 1 \\
\text { variance } \\
(\%)\end{array}$ & $\begin{array}{l}U \text { mode } 1 \\
\text { PC } R \text { and } \\
\text { heading }\end{array}$ & $\begin{array}{l}V \text { Mode } 1 \\
\text { PC } R \text { and } \\
\text { heading }\end{array}$ \\
\hline $\begin{array}{l}\text { NOS01 } \\
\text { May 03-July 10, } 1988\end{array}$ & 82 & 53 & $\begin{array}{l}0.60 \\
10^{\circ}\end{array}$ & $\begin{array}{l}-0.72 \\
98^{\circ}\end{array}$ \\
\hline $\begin{array}{l}\text { NOS01 } \\
\text { July } 12-\text { December } 31 \text {, } \\
\quad 1988\end{array}$ & 74 & 50 & $\begin{array}{l}0.67 \\
4^{\circ}\end{array}$ & $\begin{array}{l}-0.74 \\
98^{\circ}\end{array}$ \\
\hline $\begin{array}{l}\text { NOS04 } \\
\text { May 03-June 07, } 1988\end{array}$ & 86 & 81 & $\begin{array}{l}0.92 \\
38^{\circ}\end{array}$ & $\begin{array}{l}-0.89 \\
132^{\circ}\end{array}$ \\
\hline $\begin{array}{l}\text { NOS06 } \\
\text { May 03-June 07, } 1988\end{array}$ & 76 & 72 & $\begin{array}{l}0.86 \\
62^{\circ}\end{array}$ & $\begin{array}{l}-0.82 \\
116^{\circ}\end{array}$ \\
\hline $\begin{array}{l}\text { NOS07 } \\
\text { May 06-July 16, } 1990\end{array}$ & 90 & 51 & $\begin{array}{l}0.83 \\
58^{\circ}\end{array}$ & $\begin{array}{l}-0.71 \\
71^{\circ}\end{array}$ \\
\hline
\end{tabular}


Table 4 Estimates of Kelvin number $K e=B f / c$ in the vicinity of the NOS ADCP moorings derived from channel surface width $B$ and phase speed $c$ associated with the first dynamic mode computed from Brunt-Vaisala profiles obtained from NOS hydrographic stations located in Fig. 2

\begin{tabular}{llll}
\hline NOS hydro. station & $B(\mathrm{~km})$ & $c(\mathrm{~m} / \mathrm{s})$ & $K e$ \\
\hline A2 & & & \\
$\quad$ June 13, 1988 & 3.1 & 0.21 & 1.4 \\
$\quad$ July 11, 1988 & - & 0.25 & 1.2 \\
A3 & & & \\
$\quad$ June 13, 1988 & 2.5 & 0.23 & 1.0 \\
$\quad$ July 12, 1988 & - & 0.15 & 1.5 \\
B2 & & & \\
June 13, 1988 & 9.3 & 0.28 & 3.1 \\
$\quad$ July 12, 1988 & - & 0.19 & 4.5 \\
D3 & & & \\
$\quad$ June 14, 1988 & 15.2 & 0.20 & 6.83 \\
July 13, 1988 & - & 0.26 & 5.79 \\
\hline
\end{tabular}

Western LIS exhibits longitudinal density gradients estimated from hydrographic data at stations in Fig. 2 to be approximately $2.5 \times 10^{-4} \mathrm{~kg} / \mathrm{m}^{4}$ in the vicinity of station B2. There is evidence that longitudinal gradients increase toward the west. It also exhibits comparable lateral density gradients estimated to be approximately $5.0 \times 10^{-5} \mathrm{~kg} / \mathrm{m}^{4}$ in the vicinity of station B2. These gradients are associated with the buoyancy source represented by the East River in the far western Sound which supports a buoyant coastal flow directed eastward along the north shore of Long Island. $\mathrm{Li}$ and $\mathrm{Li}$ (2011) have investigated straining mechanisms by which wind-driven longitudinal and lateral flows affect stratification in a partially mixed estuary. They have considered a range of $K e$ and $W$ which are relevant to our observations. Their results for low $\mathrm{Ke}$ and $|W|>1.8$ emphasized that although the stratification decreases under both up-estuary and down-estuary winds, it experiences significantly larger reductions and takes longer to recover under the up-estuary winds. For $\mathrm{Ke}$ significantly greater than 1 , their results show that lateral straining offsets the effects of longitudinal straining and that the reduction in stratification under the up-estuary winds is markedly reduced from that found for the non-rotating case.

\section{Conclusions}

From an analysis of the relationship between estuarine exchange flow from ADCP data and axial winds, we are able to obtain estimates for $W$ which vary from approximately 0.75 to 2.5 for wind speed varying from 5 to $10 \mathrm{~cm} / \mathrm{s}$. This indicates that winds can significantly modify stratification within the estuary, and it places western LIS near the border separating a mixing dominated from a straining-dominated regime which was shown by CS to be $W \sim 1.8$. That $W$ within western LIS is below 1.8 for winds typically encountered indicates that wind- induced modifications in stratification are associated with straining rather than mixing, that down-estuary winds would produce an increase in stratification rather than a reduction that could be caused if mixing dominated.

EOF results applied to ADCP data show that dominant mode of current response is vertically sheared axial current responding to axial winds. Analysis of $N^{2}$ profiles from available hydrographic data shows that in this diverging channel, there are very significant variations in which $K e$ increases from approximately 1 in the western narrows to approximately 6 in the wide eastern portion of the channel. EOF results confirm that in wider sections of the channel with large $\mathrm{Ke}$ axial winds produce significant vertically sheared lateral currents consistent with the influence of rotation.

From analysis of current observations conclude that the strong negative correlation between inter-annual variations in the duration of summertime hypoxia estimated by CTDEP and the occurrence of northeasterly winds is consistent with straining of the axial density gradient by axial winds. The strong negative correlation between duration at NYC DEP station E10 and occurrence of northeasterly winds is also consistent with this hypothesis. In light of results by $\mathrm{Li}$ and Li (2011) which emphasize that lateral straining offsets longitudinal straining in regions where $K e$ is significantly greater than 1 , we conclude that longitudinal straining is most effective in modifying stratification in the western portion of the basin. The positive correlation between CTDEP duration and northwesterly winds is also consistent with axial straining because winds from $300^{\circ} \mathrm{T}$ have a component in the axial direction within the eastern half of the basin.

Composite analyses by Bratton et al. (2013) provide a detailed description of synoptic systems associated with hypoxic variability in western LIS which emphasize the importance of summertime high-pressure systems. One conclusion from the results presented here is that the frequency of passage of summertime high-pressure systems to the north of LIS is extremely important in controlling both the duration and the extent of summertime hypoxia.

Acknowledgments R. Wilson, B. Colle, S. Bratton, and J. Wang acknowledge support under project R/CE-30-NYCT funded under USEPA award LI-97241708-0 to the Research Foundation of SUNY on behalf of New York Sea Grant.

Open Access This article is distributed under the terms of the Creative Commons Attribution License which permits any use, distribution, and reproduction in any medium, provided the original author(s) and the source are credited.

\section{References}

Bratton, S.D., B.A. Colle and Wilson,R.E. 2013. Synoptic flow patterns and decadal variations of wind-induced mixing over western LIS (Submitted to Journal of Geophysical Research) 
Chen, S.N., and L.P. Sanford. 2009. Axial wind effects on salinity structure and longitudinal salt transport in idealized, partiallymixed estuaries. Journal of Physical Oceanography 39: 1905-1920.

Connecticut Department of Environmental Protection. 2009. LIS Hypoxia Season Review 2009, Hartford, CT, 23 pp

Earwaker, K. L. 1990. LIS Oceanographic Project: 1988-1990. NOS Oceanographic Circulation Survey Report No. 10. US Department of Commerce, National Oceanic and Atmospheric Administration, Rockville, MD

Forrest, D.R., R.D. Hetland, and S.F. DiMarco. 2011. Multivariable statistical regression models of the areal extent of hypoxia over the Texas-Louisiana continental shelf. Environmental Research Letters 6: $1-10$.

Garvine, R.W. 1995. A dynamical system for classifying buoyant coastal discharges. Continental Shelf Research 15(13): 1585-1596. doi:10. 1016/0278-4343(94)00065-U.

Hansen, D.V., and M. Rattray. 1965. Gravitational circulation in straits and estuaries. Journal of Marine Research 23: 104-122.

Hetland, R.D., and S.F. DiMarco. 2008. How does the character of oxygen demand control the structure of hypoxia on the TexasLouisiana continental shelf? Journal of Marine Systems 70: 49-62.

Li, Y., and M. Li. 2011. Effects of winds on stratification and circulation in a partially mixed estuary. Journal of Geophysical Research 116, C12012. doi:10.1029/2010JC006893.

Li, Y., and M. Li. 2012. Wind-driven lateral circulation in a stratified estuary and its effects on the along-channel flow.
Journal of Geophysical Research 117, C09005. doi:10.1029/ 2011JC007829.

O'Donnell, J., H.G. Dam, W.F. Bohlen, W. Fitzgerald, P.S. Gay, A.E. Houk, D.C. Cohen, and M.M. Howard-Strobel. 2008. Intermittent ventilation in the hypoxic zone of western Long Island Sound during the summer of 2004. Journal of Geophysical Research 113: C09025. doi:10.1029/2007JC004716.

Officer, C.B. 1976. Physical oceanography of estuaries, 465. New York: Wiley.

Scully, M.E., C.T. Friedrichs, and J.M. Brubaker. 2005. Control of estuarine stratification and mixing by wind-induced straining of the estuarine density field. Estuaries 28: 321-326.

Scully, M.E. 2010a. The importance of climate variability to wind-driven modulation of hypoxia in Chesapeake Bay. Journal of Physical Oceanography 40: 1435-1440.

Scully, M.E. 2010b. Wind modulation of dissolved oxygen in Chesapeake Bay. Estuaries and Coasts 33: 1164-1175.

Weisberg, R.H. 1976. The nontidal flow in the Providence River of Narragansett Bay: a stochastic approach to estuarine circulation. Journal of Physical Oceanography 6: 721-734.

Weisberg, R.H., and L. Zheng. 2003. How estuaries work: a Charlotte Harbor example. Journal of Marine Research 61: 635-657.

Wilson, R.E., R.L. Swanson, and H.A. Crowley. 2008. Perspectives on long-term variations in hypoxic conditions in Western LIS. Journal of Geophysical Research 113, C12011. doi:10.1029/ 2007JC004693. 